\title{
On the possible interconversion between pairs of deuterated isotopomers of methanol, its ion, and its protonated ion in star-forming regions
}

\author{
Y. Osamura ${ }^{1}$, H. Roberts ${ }^{2}$, and E. Herbst ${ }^{3}$ \\ ${ }^{1}$ Department of Chemistry, Rikkyo University, 3-34-1 Nishi-ikebukuro, Tokyo 171-8501, Japan \\ 2 Department of Physics, The Ohio State University, Columbus, OH 43210, USA \\ ${ }^{3}$ Departments of Physics, Chemistry, and Astronomy, The Ohio State University, Columbus, OH 43210, USA
}

Received 28 November 2003 / Accepted 7 April 2004

\begin{abstract}
Deuterated isotopomers of methanol have been detected both in hot cores and in the protostellar source IRAS 16293-2422. It is currently thought that these species are formed on cold grain surfaces in a previous era by the hydrogenation and deuteration of $\mathrm{CO}$ via reactions with atomic $\mathrm{H}$ and D. Methanol and its singly, doubly, and multi-deuterated isotopomers then evaporate or are sputtered into the gas as star formation occurs. In studying the post-evaporative gas-phase chemistry of these isotopomers, it is important to know if pairs of isotopomers with $\mathrm{D}$ atoms in different places (e.g. $\mathrm{CH}_{3} \mathrm{OD}$ and $\mathrm{CH}_{2} \mathrm{DOH}$ ) can be interconverted or whether they can be viewed as separate entities with depletion mechanisms that are independent of each other. Here we show that it is difficult to exchange protons and deuterons on the two different parts of the methanol backbone. It is then possible that $\mathrm{CH}_{3} \mathrm{OD}$ can be destroyed on a much faster time scale than $\mathrm{CH}_{2} \mathrm{DOH}$, an explanation that may partially explain the relatively low abundance of the former in IRAS 16293-2422.
\end{abstract}

Key words. astrochemistry - molecular processes - ISM: abundances - ISM: molecules - ISM: individual: IRAS 16293-2422

\section{Introduction}

The study of deuterated isotopomers is telling us much about the physical and chemical conditions in an assortment of environments of the interstellar medium (Millar 2003; Roberts \& Millar 2000a,b; Bacmann et al. 2003). Although much of the deuterium fractionation occurs in the gas-phase under cold conditions, the detection of high abundances of $\mathrm{D}_{2} \mathrm{CO}$ and assorted deuterated isotopomers of methanol in starforming regions (Cecarelli et al. 2002; Parise et al. 2002, 2003, $2004)$ is particularly challenging to modelers. The explanation for the methanol isotopomers can only be attempted using surface chemistry (Charnley et al. 1997): in a previous colder era, $\mathrm{CO}$ produced in the gas accretes onto the mantles of dust particles, where it is converted into formaldehyde, methanol, and their deuterated isotopomers by reactions with $\mathrm{H}$ and $\mathrm{D}$ atoms landing on the grains and diffusing rapidly over their surfaces. Once these assorted species are produced, they are thought to remain on grain surfaces until the onset of star formation, when simple evaporation due to rising temperatures or sputtering due to high-velocity winds results in the desorption of the species.

In formulating a detailed theory of the post-evaporative gasphase abundances of the deuterated isotopomers of methanol,

Send offprint requests to: $\mathrm{E}$. Herbst, e-mail: herbst@mps. ohio-state.edu it is necessary to consider what happens to these species once they are in the gas. It is important to realize that all but the fully deuterated one can be divided into pairs, in which a deuteron exists on either the $\mathrm{C}$-end or the O-end of the molecule; viz., $\mathrm{CH}_{3} \mathrm{OD}-\mathrm{CH}_{2} \mathrm{DOH}, \mathrm{CH}_{2} \mathrm{DOD}-\mathrm{CHD}_{2} \mathrm{OH}$, and $\mathrm{CHD}_{2} \mathrm{OD}-\mathrm{CD}_{3} \mathrm{OH}$. The depletion of all of these species occurs by ion-molecule reactions, which lead to protonation, charge exchange, and other products. Once the isotopomers are protonated or ionized, it is possible that, with enough internal energy, a pair of $\mathrm{D}$ and $\mathrm{H}$ atoms can rearrange between the $\mathrm{C}$ - and O-ends efficiently so that the two ions should really be considered one rather floppy system. Even if this rearrangement does not occur during the lifetime of the protonated ions, it might occur during their dissociative recombination with electrons. And following dissociative recombination, it might occur between the regenerated neutral methanol isotopomers if they are sufficiently energized. Rearrangement by any of the above mechanisms can erase potential differences in the rates of depletion of the isotopomeric neutral pairs. On the other hand, if interconversion does not occur appreciably, the depletion of the two isotopomers should be distinct, and it would be possible for one to have a much faster depletion rate than the other.

In this paper, we report detailed quantum chemical calculations on the internal rearrangements possible in energized normal methanol, ionized methanol, and protonated methanol, 
during the dissociative recombination of protonated methanol, the reactions of protonated and ionized methanol with hydrogen atoms, and even during the reaction between neutral methanol and hydrogen atoms. In all of these cases, we find that exchange between protons (or protons and deuterons) from the two ends of the molecular structure is unlikely to occur efficiently. Thus, we can, for example, think of the singly deuterated isotopomers $\mathrm{CH}_{3} \mathrm{OD}$ and $\mathrm{CH}_{2} \mathrm{DOH}$ as quite distinct species with possibly different depletion mechanisms and time scales. Such an argument, first proposed by Charnley et al. (1997), can be used to explain the low abundance of the former compared with the latter in the protostellar source IRAS 16293-2422. In this argument, protonation of $\mathrm{CH}_{3} \mathrm{OD}$ leads to its destruction at a more rapid rate than protonation of $\mathrm{CH}_{2} \mathrm{DOH}$ because $\mathrm{CH}_{2} \mathrm{DOH}_{2}^{+}$reforms $\mathrm{CH}_{2} \mathrm{DOH}$ upon dissociative recombination, whereas dissociative recombination of $\mathrm{CH}_{3} \mathrm{ODH}^{+}$leads to both $\mathrm{CH}_{3} \mathrm{OD}$ and $\mathrm{CH}_{3} \mathrm{OH}$.

In our calculations, we will confine ourselves to the exchange of protons between the $\mathrm{C}$ - and the O-ends of methanolrelated molecules. It is not necessary to specifically follow deuterons since the reaction pathways for $\mathrm{H}-\mathrm{H}$ and $\mathrm{H}-\mathrm{D}$ exchange are the same, according to the Born-Oppenheimer approximation. Thus, if we conclude that a proton cannot go from one end of methanol to the other, or that simultaneous transfer of two protons between the $\mathrm{C}$ - and $\mathrm{O}$-ends is impossible, the same holds true for motions involving a proton and a deuteron. We will consider two types of processes: (i) motion of one proton (known as an $\mathrm{H}$-shift), and (ii) simultaneous exchange of two protons (known as synchronous $\mathrm{H}-\mathrm{H}$ exchange). Note that two consecutive $\mathrm{H}$-shift motions are needed to effect an exchange that is not synchronous.

The remainder of the paper is organized in the following manner. Following a brief discussion of quantum chemical methods in Sect. 2, we consider the possibility of protonproton exchanges in energized methanol, its ion, and its protonated form in Sect. 3. In Sect. 4, we consider the possibility of exchange during chemical reactions. Finally, in Sect. 5, we employ what has been learned in new detailed models of IRAS 16293-2422 and the Orion Compact Ridge and compare our results with observations of the deuterated isotopomers of methanol and selected other species.

\section{Quantum chemical calculations}

We have applied the hybrid density functional B3LYP method with a $6-311 \mathrm{G}(\mathrm{d}, \mathrm{p})$ basis set to calculate the potential energy surfaces for the exchange of protons between the $\mathrm{C}$ and $\mathrm{O}$-ends of methanol, its ion, and its protonated form. We have also calculated potential surfaces relevant to the dissociative recombination of $\mathrm{CH}_{3} \mathrm{OH}_{2}^{+}$and the formation of assorted neutral fragments, as well as energy barriers (corresponding to so-called transition state structures) for the reactions of hydrogen atoms with (i) neutral methanol and (ii) protonated methanol. In addition, the potential surfaces for the reactions between protons and methanol have been looked at. All computations were carried out with the Gaussian 98 program suite (Frisch et al. 1998). The structures on the potential energy surfaces were confirmed to be energy minima or

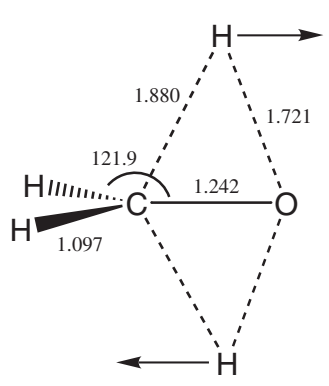

$\mathrm{H}-\mathrm{H}$ exchange TS

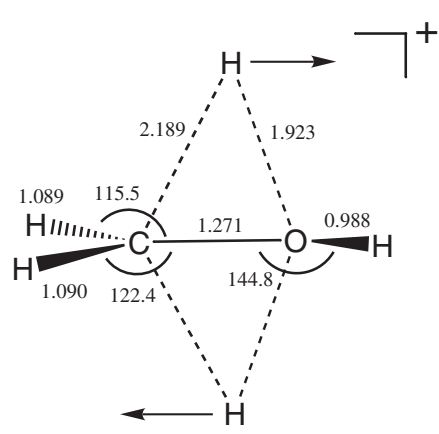

$\mathrm{H}-\mathrm{H}$ exchange $\mathrm{TSH}^{+}$
Fig. 1. Optimized structures of transition states for the synchronous hydrogen-exchange reaction in methanol $(\mathrm{H}-\mathrm{H}$ exchange TS) and in protonated methanol $\left(\mathrm{H}-\mathrm{H}\right.$ exchange $\left.\mathrm{TSH}^{+}\right)$obtained with the B3LYP method. Bond distances are in $\AA$ and bond angles are in degrees. The relative transition state energies with the $\operatorname{CCSD}(\mathrm{T})$ method are $+148.6 \mathrm{kcal} \mathrm{mol}^{-1}$ for TS and $+148.9 \mathrm{kcal} \mathrm{mol}^{-1}$ for $\mathrm{TSH}^{+}$.

transition states (saddle points) by a vibrational analysis. In order to refine the relative energies along the assorted potential energy surfaces, we utilized the $\operatorname{CCSD}(\mathrm{T})$ method with the augmented correlation-consistent polarized-valence triplezeta basis set (aug-cc-pVTZ) of Dunning (1989) at the geometries obtained with the B3LYP method. The relative energies presented in this paper are corrected by zero-point vibrational energies obtained with the B3LYP method without scaling. The energies are expressed in units of $\mathrm{kcal} \mathrm{mol}^{-1}$, where $1 \mathrm{kcal} \mathrm{mol}^{-1}=503 \mathrm{~K}$.

\section{Exchange following reaction}

We start by discussing the possibility that protons from the Cand O-ends of neutral, ionized, and protonated methanol can exchange spontaneously. This is most likely to occur following a chemical reaction in which the methanol-like species possess internal energy. If two hydrogen atoms on the $\mathrm{C}$-atom and $\mathrm{O}$-atom, respectively, can exchange, $\mathrm{H}-\mathrm{D}$ exchange is possible between the singly deuterated pairs $\mathrm{CH}_{3} \mathrm{OD}-\mathrm{CH}_{2} \mathrm{DOH}$, $\mathrm{CH}_{3} \mathrm{OD}^{+}-\mathrm{CH}_{2} \mathrm{DOH}^{+}$, and $\mathrm{CH}_{3} \mathrm{OHD}^{+}-\mathrm{CH}_{2} \mathrm{DOH}_{2}^{+}$, and their multiply deuterated analogs. Note that the deuterated pairs of isomers do have slightly different zero-point energies, but this will only affect a dynamic equilibrium, not prohibit it from occurring. These energy differences are not large; we calculate for example that $\mathrm{CH}_{3} \mathrm{OD}$ is more stable than $\mathrm{CH}_{2} \mathrm{DOH}$ by about $50 \mathrm{~K}$.

Figure 1 shows transition state structures for neutral and protonated methanol for the case of synchronous $\mathrm{H}-\mathrm{H}$ exchange. The calculated energies of these transition state structures compared with methanol and protonated methanol are $148.6 \mathrm{kcal} \mathrm{mol}^{-1}$ and $148.9 \mathrm{kcal} \mathrm{mol}^{-1}$, respectively, at our highest level of calculation. These very large values mean that isomerization does not occur via this mechanism unless the species are very internally excited. Unlike the protonated ion, the methanol ion does not show a true transition state for synchronous $\mathrm{H}-\mathrm{H}$ exchange, so the process does not occur at any energy. 


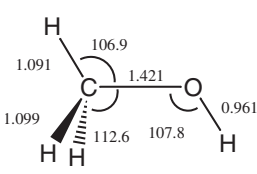

$\mathrm{CH}_{3} \mathrm{OH} 0.0(0.0)$

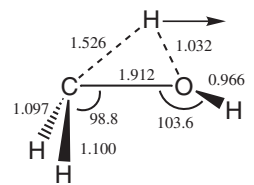

H-shift TS +82.4 (+81.0)

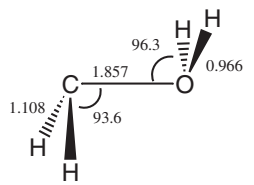

$\mathrm{CH}_{2} \mathrm{OH}_{2}+81.1(+80.8)$

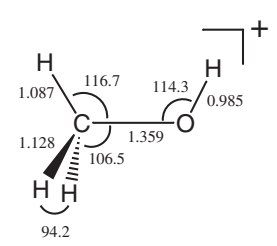

$\mathrm{CH}_{3} \mathrm{OH}^{+} 0.0(0.0)$

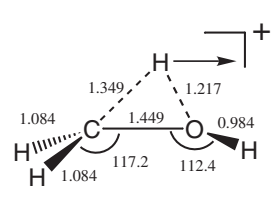

H-shift TS $^{+}+25.1(+30.5)$

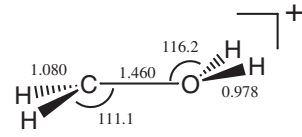

$\mathrm{CH}_{2} \mathrm{OH}_{2}^{+}-6.8(-1.4)$
Fig. 2. The upper panels show the optimized structures of methanol, its hydrogen-shift transition state, and the isomer $\mathrm{CH}_{2} \mathrm{OH}_{2}$, while the lower panels show the structures of the methanol ion, its hydrogenshift transition state, and the isomer $\mathrm{CH}_{2} \mathrm{OH}_{2}^{+}$. Bond distances are in $\AA$ and bond angles are in degrees. The numbers outside of and in parentheses are the relative energies in $\mathrm{kcal} \mathrm{mol}^{-1}$ obtained with the $\operatorname{CCSD}(\mathrm{T})$ and B3LYP methods.

Figure 2 shows transition state structures and energies for a simple proton shift from the $\mathrm{C}$-end to the $\mathrm{O}$-end, or its reverse, in methanol and its ion. In this case, the full exchange would also require motion of another proton in the opposite direction over the same transition state. The transition state energies are not as large as for the simultaneous $\mathrm{H}-\mathrm{H}$ transfer but they are still sufficiently large so that spontaneous isomerization does not happen under thermal interstellar conditions. But we must also consider isomerization following chemical reactions in which the products possess large amounts of internal energy which can only be radiated away. The protonated ion does not possess a transition state for the single $\mathrm{H}$-shift mechanism, so, as is the case for the normal ion attempting to undergo synchronous $\mathrm{H}-\mathrm{H}$ exchange, the process of a single $\mathrm{H}$-shift or consecutive $\mathrm{H}$-shifts does not occur for protonated methanol.

\subsection{Internally excited methanol}

The most likely reaction sequence leading to excited neutral methanol involves protonation followed by dissociative recombination to reform methanol:

$$
\begin{aligned}
& \mathrm{CH}_{3} \mathrm{OH}+\mathrm{X}-\mathrm{H}^{+} \longrightarrow \mathrm{CH}_{3} \mathrm{OH}_{2}^{+}+\mathrm{X}, \\
& \mathrm{CH}_{3} \mathrm{OH}_{2}^{+}+\mathrm{e}^{-} \longrightarrow \mathrm{CH}_{3} \mathrm{OH}+\mathrm{H},
\end{aligned}
$$

where $\mathrm{X}-\mathrm{H}^{+}$represents a protonating ion, and protonation occurs on the O-end. The exothermicity of the dissociative recombination reaction, discussed more fully in Sect. 4 , is calculated to be $134.6 \mathrm{kcal} \mathrm{mol}^{-1}$, and a significant amount of that energy is likely to be present initially in the methanol product. Among the different unimolecular reactions that can spontaneously occur from energized methanol is the exchange of the $\mathrm{C}$ - and O-protons. Since the barrier for synchronous H-H transfer (see Fig. 1) exceeds the maximum internal energy that methanol can possess, the exchange via two consecutive $\mathrm{H}$-shifts is the only possibility. For this mechanism, the two transition states, each at an energy of $82.4 \mathrm{kcal} \mathrm{mol}^{-1}$, lie considerably below $134.6 \mathrm{kcal} \mathrm{mol}^{-1}$. Of course, not all of the $134.6 \mathrm{kcal} \mathrm{mol}^{-1}$ will go into internal energy of methanol product, since there is also translational energy between the methanol and the $\mathrm{H}$ atom. In addition, only vibrational energy is efficient at promoting isomerization; rotational energy has a much more subtle effect (Herbst et al. 2000).

There have been very few theoretical and experimental studies of the vibrational energy distribution of neutral products of dissociative recombination reactions. Bates (1993) developed a classical theory with several mechanisms, including the so-called "impulse" and "relic" processes. Tomasehvsky et al. (1998) developed a quantum mechanical treatment, and applied it to the case of the $\mathrm{CO}$ product of $\mathrm{HCO}^{+}+\mathrm{e}^{-}$, which had been studied experimentally in its $a^{3} \Pi$ state by Adams and co-workers (Adams \& Babcock 1994; Butler et al. 1997). More limited experimental studies of the vibrational distribution of $\mathrm{OH}$ product from an assortment of dissociative recombination reactions were reported by Herd et al. (1990). The general picture from all of these studies is that for a diatomic product, the vibrational distribution peaks at or near the ground state, and gradually declines as the vibrational quantum number increases. In most cases, the majority of the energy on average seems to be in modes other than vibration, most probably translation. The extension to a polyatomic neutral product such as methanol, with many modes of vibration, is uncertain, but it is likely that product translational energy must be large since dissociative recombination cannot occur unless the products rapidly leave the vicinity of configuration space in which the parent product neutral is formed. Thus, although the vibrational distribution of energized methanol emerging as a product of dissociative recombination is uncertain, it is most likely that only a small fraction of the product molecules will possess enough vibrational energy to undergo isomerization, since in this instance the threshold for isomerization requires over 60 percent of the exothermicity of the dissociative recombination reaction.

To estimate the actual unimolecular rate of isomerization of methanol via two H-shifts as a function of vibrational energy, we can use RRKM theory (Smith 1980; Holbrook et al. 1996). Let us first consider a single $\mathrm{H}$-shift from methanol to its isomer $\mathrm{CH}_{2} \mathrm{OH}_{2}$. In the RRKM approach, the isomerization rate $k_{\text {iso }}$ is given by the expression

$k_{\text {iso }}=\frac{\prod_{i=1}^{s} v_{i}}{\prod_{i=1}^{s-1} v_{i}^{\dagger}} \frac{\left(E-D+a^{\dagger} E_{\mathrm{z}}^{\dagger}\right)^{s-1}}{\left(E+a E_{\mathrm{z}}\right)^{s-1}}$,

where the $v_{i}$ are the vibrational frequencies, $D$ is the transition state energy $\left(82.4 \mathrm{kcal} \mathrm{mol}^{-1}\right), E$ is the total vibrational internal energy, $E_{\mathrm{z}}$ is the zero-point energy, $s=12$ is the number of vibrational degrees of freedom, and $a$ is an empirical factor between zero and unity. Parameters with the $\dagger$ symbol refers to the transition state, while those without this symbol refer to normal methanol. The RRKM expression used here is without tunneling, and so is only valid if the total vibrational energy exceeds the transition state barrier of $82.4 \mathrm{kcal} \mathrm{mol}^{-1}$. Using calculated values of the vibrational frequencies, we estimate that the rate of isomerization at energies very close to the vibrational energy threshold of $82.4 \mathrm{kcal} \mathrm{mol}^{-1}\left(\approx 10^{6} \mathrm{~s}^{-1}\right)$ is still 
Table 1. Possible products and required energies $\left(\mathrm{kcal} \mathrm{mol}^{-1}\right)$ for the unimolecular dissociation of excited methanol.

\begin{tabular}{lrr}
\hline \hline Products & \multicolumn{2}{c}{ Energy } \\
& B3LYP & CCSD $(\mathrm{T})$ \\
\hline $\mathrm{CH}_{3} \mathrm{O}+\mathrm{H}$ & 96.8 & 102.1 \\
$\mathrm{CH}_{2} \mathrm{OH}+\mathrm{H}$ & 91.5 & 94.0 \\
$\mathrm{CH}_{2}+\mathrm{H}_{2} \mathrm{O}$ & 95.6 & 89.2 \\
$\mathrm{CH}_{2} \mathrm{O}+\mathrm{H}_{2}$ & 16.9 & 20.4 \\
$\mathrm{CH}_{3}+\mathrm{OH}$ & 85.4 & 87.8 \\
\hline
\end{tabular}

much faster than the radiative relaxation rate of vibrationally energized methanol, which occurs at a rate of $10^{2-3} \mathrm{~s}^{-1}$ (Herbst 1982; see his Fig. 3). Although we have only calculated the rate for a single $\mathrm{H}$-shift to form $\mathrm{CH}_{2} \mathrm{OH}_{2}$; a double shift is likely to follow with an overall rate a sizable fraction of that of the single shift, because $\mathrm{CH}_{2} \mathrm{OH}_{2}$ lies at a significantly higher energy than methanol and so will likely re-isomerize with or without a net exchange. The rate coefficient for $\mathrm{D}-\mathrm{H}$ exchange via two shifts is likely to be somewhat smaller still because of mass and statistical effects, but RRKM theory still predicts it to be dominant over radiative relaxation at almost all energies above threshold. So, exchange, including that of $\mathrm{D}$ and $\mathrm{H}$ atoms, can occur if the energized methanol product possesses a sufficient amount of internal vibrational energy. This result must be viewed with some caution, since it is likely that the statistical theory overestimates the rate of isomerization given its steric complexity. This caution, combined with the unlikelihood that a sufficient amount of vibrational energy $\left(>82.4 \mathrm{kcal} \mathrm{mol}^{-1}\right)$ is available in the first place, suggests strongly that most energized methanol molecules relax radiatively without undergoing isomeric shifts. We discuss this point further in the section below on dissociative recombination. It is interesting to note that in an earlier paper on HNC-HCN isomerization (Herbst et al. 2000), we concluded that dissociative recombination of the parent ion $\mathrm{HCNH}^{+}$does not lead to enough internal energy for facile interconversion of the two isomers. A different conclusion was reached, however, for $\mathrm{HCN}$ and $\mathrm{HNC}$ products of the neutral-neutral reactions $\mathrm{C}+\mathrm{NH}_{2}$ and $\mathrm{N}+\mathrm{CH}_{2}$.

In addition to the single- $\mathrm{H}$ and double- $\mathrm{H}$ shift isomerization, dissociation processes that the excited methanol can undergo are listed in Table 1. As can be seen, dissociation of methanol into $\mathrm{CH}_{3} \mathrm{O}+\mathrm{H}, \mathrm{CH}_{2} \mathrm{OH}+\mathrm{H}, \mathrm{CH}_{2}+\mathrm{H}_{2} \mathrm{O}$ and $\mathrm{CH}_{3}+\mathrm{OH}$ requires almost the entire internal energy of the excited methanol so that the four processes are quite unlikely. The one major exception is the dissociation of methanol to form formaldehyde and molecular hydrogen, which requires only $20.4 \mathrm{kcal} \mathrm{mol}^{-1}$, as shown in Table 1 . But this process must occur over a very large activation energy barrier (Kline \& Penner 1982) and, if it occurs at all, will not have the effect of interconverting isotopomeric pairs. We have calculated the activation energy to be $100.5 \mathrm{kcal} \mathrm{mol}^{-1}$.

\subsection{Internally excited ions}

For protonated methanol, excitation occurs during formation via reaction (1). For example, the exothermicity for the protonation reaction between methanol and $\mathrm{H}_{3}^{+}$is $84 \mathrm{kcal} \mathrm{mol}^{-1}$, while that for the analogous reactions involving other major protonating ions is at most half as great. Once again, all of this energy does not go into protonated methanol; some goes into translational energy and some goes into the neutral product, e.g., $\mathrm{H}_{2}$. Even if protonated methanol is the recipient of all of the reaction exothermicity, there is still nowhere near enough energy to surmount the transition state barrier for synchronous exchange (see Fig. 1). Nor can any single H-shift occur given the saturated nature of the species. So, we find that $\mathrm{H}-\mathrm{H}$ (and by extension H-D) exchange cannot occur between pairs of protonated isotopomers of methanol.

For energized methanol ion, the only possible pathway to isomerization is shown in Fig. 2. For two single-H shifts, the transition states lie at only $25.1 \mathrm{kcal} \mathrm{mol}^{-1}$. Ionization of methanol via charge exchange with protons can lead to an internal energy of as much as $64.5 \mathrm{kcal} \mathrm{mol}^{-1}$, according to our calculations. This amount of energy is, once again, enough to allow an isomerization via two $\mathrm{H}$-shifts. The isomerization must compete with other unimolecular processes, most notably the single $\mathrm{H}$-shift reaction:

$\mathrm{CH}_{3} \mathrm{OH}^{+} \longrightarrow \mathrm{CH}_{2} \mathrm{OH}_{2}^{+}$,

which, unlike the analogous case for neutral methanol, is exothermic by $8.1 \mathrm{kcal} \mathrm{mol}^{-1}$. It is likely here that single $\mathrm{H}$-shift is favored because in a dynamic equilibrium, the lower energy isomer $-\mathrm{CH}_{2} \mathrm{OH}_{2}^{+}-$is likely to dominate. Moreover, even if exchange of the protons occurs, the ionized methanol, unlike protonated methanol, is not likely to reform neutral methanol. Thus, if we start with a deuterated isotopomer such as $\mathrm{CH}_{3} \mathrm{OD}$ and ionize it to $\mathrm{CH}_{3} \mathrm{OD}^{+}$, whether the ion can partially convert to $\mathrm{CH}_{2} \mathrm{DOH}^{+}$does not mean that the new ion can lead to the production of the isomeric pair $\mathrm{CH}_{2} \mathrm{DOH}$. Remember that recombination of ions with electrons is dissociative in nature.

Now let us consider what types of reactions can help to exchange protons/deuterons. It is important to remember here that energized species in the low density interstellar medium will typically radiate their internal energy before undergoing subsequent reactions, so that we need consider only thermal reactants.

\section{Exchange during the course of reaction}

\subsection{Reactions with atomic $H$}

Transition state structures for the reactions discussed in this section are to be found in Fig. 3, although some of the transition states including the hydrogen abstraction reaction of methanol by $\mathrm{H}$ atoms (TS4 and TS5) have already been studied by several authors (Lendvay et al. 1997; Jodkowski et al. 1999). The reaction between atomic $\mathrm{H}$ and neutral methanol has actually been studied in the laboratory, where a variety of different products are formed, all with moderate activation energy barriers (see the NIST chemical kinetics database at http://kinetics.nist.gov/index.php). In Fig. 4, we show a variety of calculated pathways for the reaction including simple exchange. Barriers with associated transition states (TS1-TS6) are found for all reactions. There 


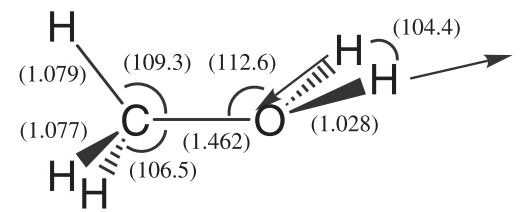

TS1

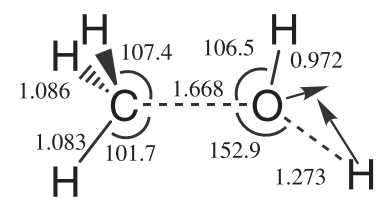

TS2

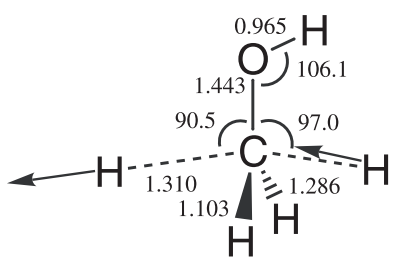

TS3

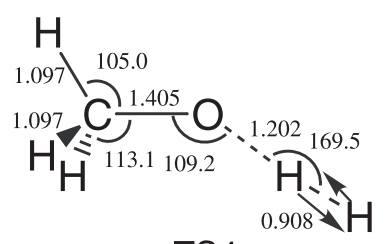

TS4

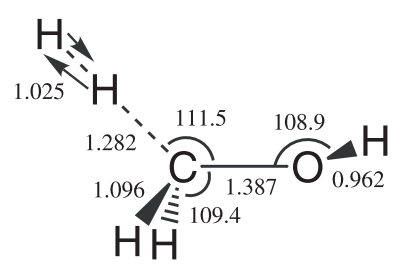

TS5<smiles>CN1CCO1</smiles>

TS6

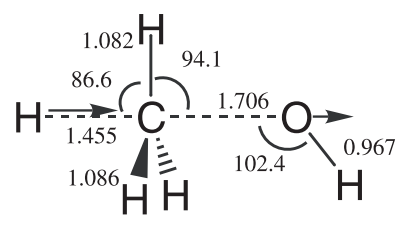

TS7
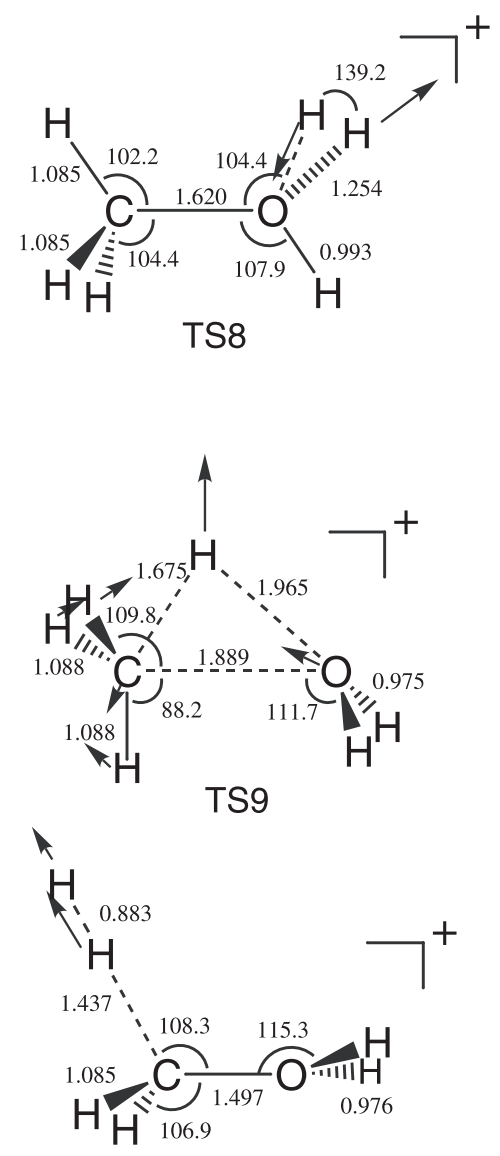

TS10

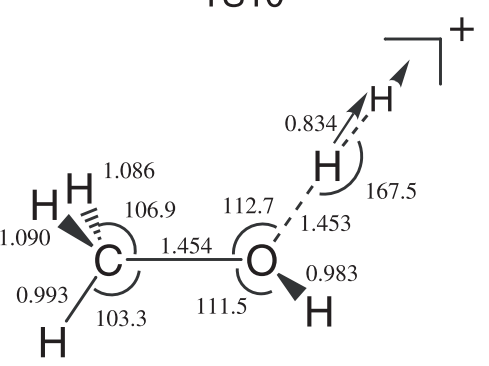

TS11

Fig. 3. Transition state structures for studied reactions calculated at the B3LYP/6-311G(d, p) level, except for TS1, which is calculated at the HF/6-311G(d, p) level. Bond distances are in $\AA$ and bond angles are in degrees.

are two transition states for $\mathrm{H}-\mathrm{H}$ exchange: TS1 and TS3. TS1 lies $20.3 \mathrm{kcal} \mathrm{mol}^{-1}$ above the reactants while TS3 lies $40.4 \mathrm{kcal} \mathrm{mol}^{-1}$ above, so that exchange does not occur under thermal interstellar conditions via either of these pathways. Moreover, neither $\mathrm{H}-\mathrm{H}$ exchange is of interest for isotopic problems because both involve exchange of one type of proton: TS1 on the O-end and TS3 on the C-end of methanol!
We have also examined the possibility of a hydrogen exchange reaction between $\mathrm{H}$ and protonated methanol. Figure 5 shows the schematic potential profile both for reaction and for exchange. The energy of the transition state TS8 for hydrogen exchange is calculated to be $48.6 \mathrm{kcal} \mathrm{mol}^{-1}$, so that once again, exchange cannot take place in the interstellar medium. Moreover, the exchange occurs fully on the oxygen end of the 


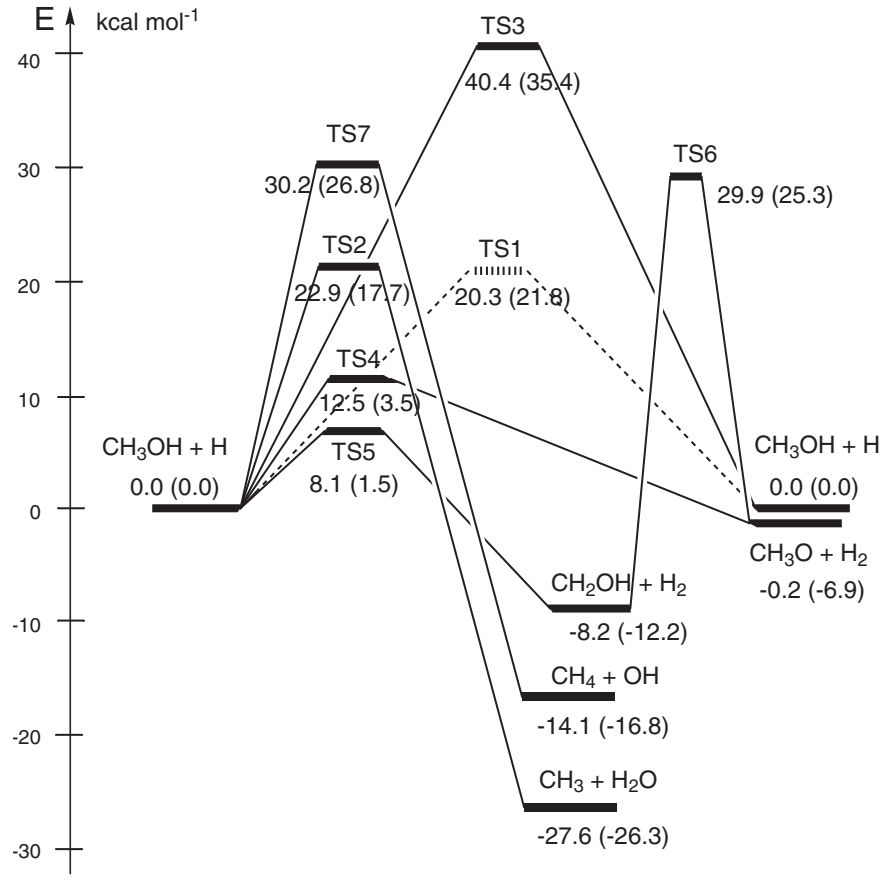

Fig. 4. Potential energy surfaces of the reactions between $\mathrm{CH}_{3} \mathrm{OH}$ and $\mathrm{H}$ atoms calculated with the $\operatorname{CCSD}(\mathrm{T}) /$ aug-cc-pVTZ method. The energy of TS1 (dashed line) is calculated with $\operatorname{CCSD}(\mathrm{T})$ method at the geometry obtained with the $\operatorname{HF} / 6-311 G(d$, p) method. The values in parentheses are the relative energies obtained with the B3LYP/6-311G(d, p) method.

molecule, and so once again is useless for exchanging protons from different ends of the molecule. Although the energy barriers for hydrogen abstraction reactions (TS10 and TS11) are lower than that for hydrogen exchange, they are also high enough to impede reaction under interstellar conditions.

Finally, consider the exothermic reaction between the methanol ion and atomic hydrogen:

$\mathrm{CH}_{3} \mathrm{OH}^{+}+\mathrm{H} \longrightarrow \mathrm{CH}_{2} \mathrm{OH}_{2}^{+}+\mathrm{H}$.

If the reaction occurs by a single $\mathrm{H}$-shift mechanism in which the $\mathrm{H}$ atom acts as a very limited chaperone, there is a significant barrier of $25.1 \mathrm{kcal} \mathrm{mol}^{-1}$, which is essentially the barrier for unimolecular isomerization. Another possibility is the barrierless formation of protonated methanol followed by a barrierless $\mathrm{H}$ atom elimination leading to the products shown. Barrierless dissociation into the fragments $\mathrm{CH}_{3}^{+}+\mathrm{H}_{2} \mathrm{O}$ may also occur. Whatever the final products, there is insufficient energy available for $\mathrm{H}-\mathrm{H}$ exchange to occur over a transition state during the lifetime of the protonated methanol complex.

\subsection{Dissociative recombination of protonated methanol and related issues}

Figure 6 shows the schematic potential energy surfaces for the ground electronic states of protonated methanol and its neutralized species $\left(\mathrm{CH}_{3} \mathrm{OH}_{2}\right)$ relevant for dissociative recombination. As can be seen, the structure for protonated methanol $\left(\mathrm{CH}_{3} \mathrm{OH}_{2}^{+}\right)$is located at a very deep minimum, while the neutralized species with the same structure does not occur at

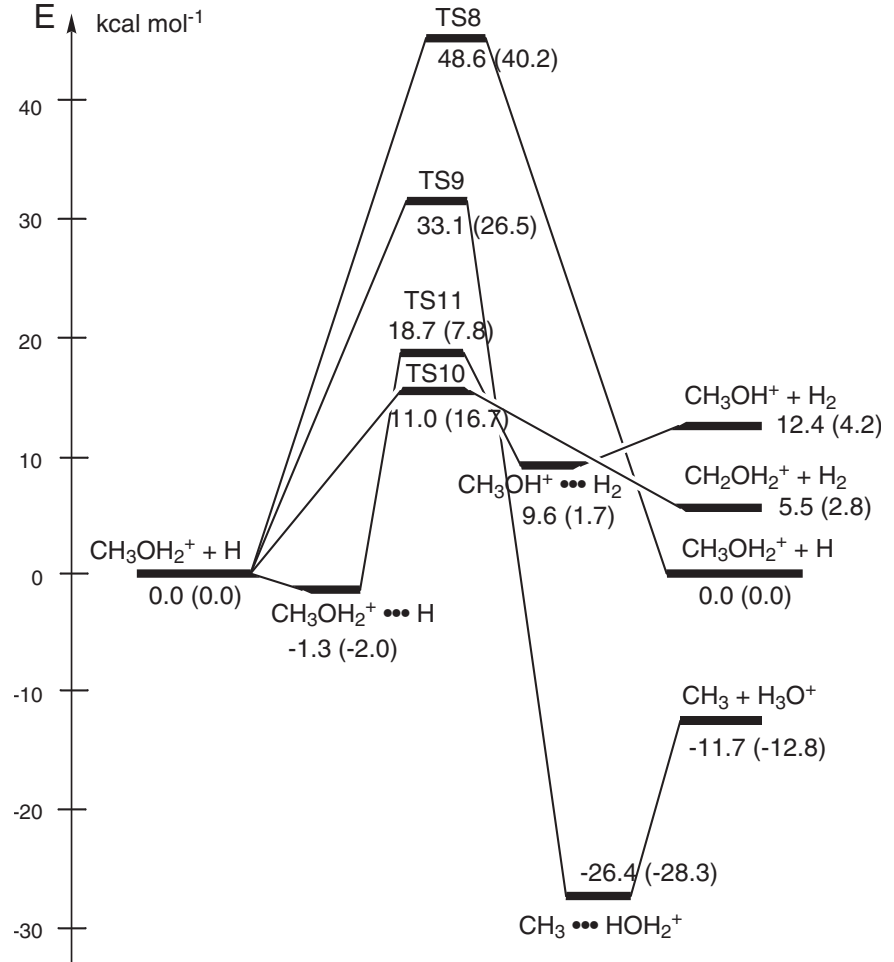

Fig. 5. Potential energy surfaces of the reaction between $\mathrm{CH}_{3} \mathrm{OH}_{2}^{+}$ and $\mathrm{H}$ atoms calculated with the $\operatorname{CCSD}(\mathrm{T}) /$ aug-cc-pVTZ method. The values in parentheses are the relative energies obtained with the B3LYP/6-311G(d, p) method.

a potential minimum although it lies considerably below the potential minimum of the ion. In order for dissociative recombination to occur at a rapid rate, either an excited repulsive potential surface of $\mathrm{CH}_{3} \mathrm{OH}_{2}$ must intersect the ionic potential around its minimum (the so-called "direct" mechanism) or the ion must initially cross over to excited Rydberg states of the neutral species, which then cross repulsive neutral states (the so-called "indirect" mechanism) (Guberman 2003).

When an electron recombines with protonated methanol, the neutralized species is calculated to lie $106.1 \mathrm{kcal} \mathrm{mol}^{-1}$ below $\mathrm{CH}_{3} \mathrm{OH}_{2}^{+}$neglecting any small kinetic energy for the incident electron, as shown in Fig. 6. This ground neutral state is not accessed directly since it does not cross the ionic state near its minimum. Nevertheless, it and excited valence states of $\mathrm{CH}_{3} \mathrm{OH}_{2}$ are repulsive and can be accessed via the indirect mechanism. The $\mathrm{CH}_{3} \mathrm{OH}_{2}$ species subequently slips down toward the exothermic products $\mathrm{CH}_{3} \mathrm{OH}+\mathrm{H}$ or $\mathrm{CH}_{3}+\mathrm{H}_{2} \mathrm{O}$ along the $\mathrm{O}-\mathrm{H}$ and $\mathrm{C}-\mathrm{O}$ bond dissociation pathways, respectively. Since re-ionization ("auto-ionization") of the parent neutral species can occur on a rapid time scale if a chemical bond is not broken even more quickly, it is obvious that a large fraction of the energy of reaction must go into the relative translational energy of the separating products. It is this necessity that limits the amount of internal vibrational energy that can accumulate in the products. Nevertheless, since the exothermicities for these two sets of products are extremely large, secondary bond dissociation might occur during the course of reaction. This type of dissociation is distinct from dissociation of energized methanol after reaction. Table 2 shows 


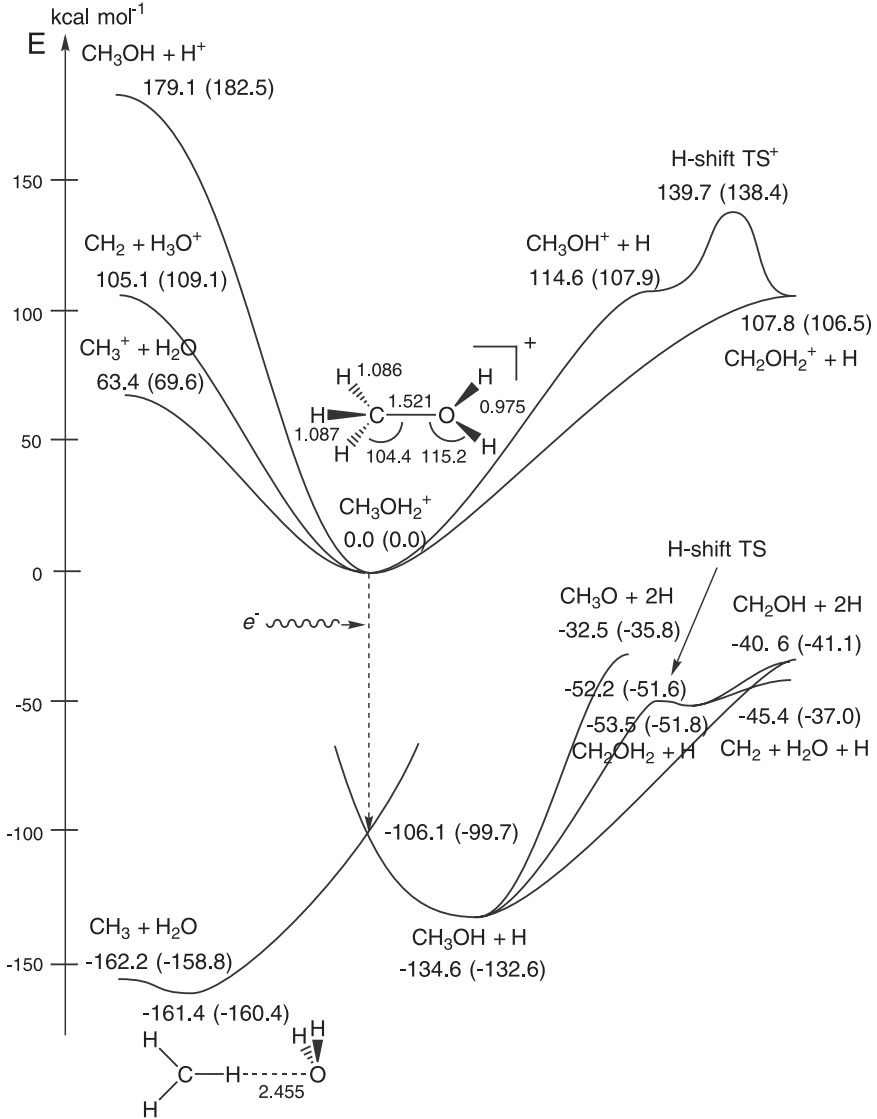

Fig. 6. Potential energy surfaces of $\mathrm{CH}_{3} \mathrm{OH}_{2}^{+}$(upper curve) and its neutralized species (lower curve) calculated by using the $\operatorname{CCSD}(\mathrm{T}) /$ aug-cc-pVTZ method at the optimized geometries obtained with the B3LYP/6-311G $(\mathrm{d}, \mathrm{p})$ method. The relative energies are shown in $\mathrm{kcal} \mathrm{mol}^{-1}$. The values in parentheses are the calculated relative energies with the B3LYP/6-311G(d, p) method. Bond distances are in $\AA$ and bond angles are in degrees.

the energetically possible primary and secondary dissociation products of $\mathrm{CH}_{3} \mathrm{OH}_{2}^{+}+\mathrm{e}^{-}$. Of the primary products, the lowest energy fragments are $\mathrm{CH}_{3}+\mathrm{H}_{2} \mathrm{O}$. Of the secondary channels, the most important probably involve elimination of a second hydrogen atom. Because the energies of $\mathrm{CH}_{3} \mathrm{O}+2 \mathrm{H}$ and $\mathrm{CH}_{2} \mathrm{OH}+2 \mathrm{H}$ are only 32.5 and $40.6 \mathrm{kcal} \mathrm{mol}^{-1}$ below the energy of $\mathrm{CH}_{3} \mathrm{OH}_{2}^{+}+\mathrm{e}^{-}$, and because the neutralized $\mathrm{CH}_{3} \mathrm{OH}_{2}$ moves rapidly on the repulsive surface towards $\mathrm{O}-\mathrm{H}$ bond rupture, the elimination of a second hydrogen atom from $\mathrm{CH}_{3} \mathrm{OH}$ seems to be improbable, but cannot be ruled out in the absence of detailed dynamical calculations given the number of storage ring measurements showing the preponderance of threebody channels (see, e.g., Semaniak et al. 1998). The formation of a hydrogen molecule from $\mathrm{CH}_{3} \mathrm{OH}_{2}^{+}+\mathrm{e}^{-}$is energetically favorable, as shown in Table 2 , but this process is only possible when a departing hydrogen atom from neutralized protonated methanol abstracts a second hydrogen atom of methanol, which is dynamically very unlikely. Most of the other exothermic fragments shown in Table 2 require significant rearrangements and do not appear to be possible.

What about the possibility that $\mathrm{H}$-atom exchange can occur before $\mathrm{CH}_{3} \mathrm{OH}_{2}$ dissociates? Since the dissociation to methanol
Table 2. Relative energies $\left(\mathrm{kcal} \mathrm{mol}^{-1}\right)$ of the possible exothermic products of $\mathrm{CH}_{3} \mathrm{OH}_{2}^{+}+\mathrm{e}^{-}$.

\begin{tabular}{lrr}
\hline \hline Species & \multicolumn{2}{c}{$\Delta E$} \\
& B3LYP & CCSD(T) \\
\hline $\mathrm{CH}_{3} \mathrm{OH}_{2}^{+}+\mathrm{e}-$ & 0.0 & 0.0 \\
$\mathrm{CH}_{3}+\mathrm{H}_{2} \mathrm{O}$ & -158.8 & -162.2 \\
$\mathrm{CH}_{3} \mathrm{OH}+\mathrm{H}$ & -132.6 & -134.6 \\
$\mathrm{CH}_{3} \mathrm{O}+2 \mathrm{H}$ & -35.8 & -32.5 \\
$\mathrm{CH}_{3} \mathrm{O}+\mathrm{H}_{2}$ & -139.4 & -134.7 \\
$\mathrm{CH}_{2} \mathrm{OH}+2 \mathrm{H}$ & -41.1 & -40.6 \\
$\mathrm{CH}_{2} \mathrm{OH}+\mathrm{H}_{2}$ & -144.7 & -142.8 \\
$\mathrm{CH}_{2} \mathrm{O}+\mathrm{H}_{2}+\mathrm{H}$ & -115.7 & -114.2 \\
$\mathrm{CH}_{4}+\mathrm{OH}$ & -149.4 & -148.7 \\
$\mathrm{HCO}_{2}+\mathrm{H}_{2}$ & -135.2 & -130.5 \\
$\mathrm{CH}_{2} \mathrm{OH} \mathrm{H}_{2}+\mathrm{H}$ & -51.8 & -53.5 \\
$\mathrm{CH}_{2}+\mathrm{H}_{2} \mathrm{O}+\mathrm{H}$ & -37.0 & -45.4 \\
\hline
\end{tabular}

and $\mathrm{H}$ occurs rapidly, the chance that protons from the $\mathrm{C}$ - and $\mathrm{O}$-ends can exchange before the formation of products is remote given the complexity of the mechanism. To quantify this conjecture, we can crudely use the expression in Eq. (3), making the additional assumption that the departing $\mathrm{H}$ atom does not change the energetics of the exchange. The result for the rate of exchange is so much slower than the rate of dissociation of $\mathrm{CH}_{3} \mathrm{OH}_{2}$, which occurs on the time scale of a vibrational period, that $\mathrm{H}$-atom exchange cannot occur.

Finally, we can use the calculated potential surface for the protonated ion to consider exchange via the reaction between $\mathrm{H}^{+}$and neutral methanol assuming that it proceeds via the protonated methanol complex. This complex will dissociate to charge exchange products, to $\mathrm{CH}_{2} \mathrm{OH}_{2}^{+}+\mathrm{H}$, and to other fragments. During the time that the complex exists, there is a finite chance that exchange can take place, because the transition state for synchronous exchange, labeled " $\mathrm{H}-\mathrm{H}$ exchange $\mathrm{TSH}^{+}$" in Fig. 1, lies about $30 \mathrm{kcal} \mathrm{mol}^{-1}$ below the energy of reactants. Nevertheless, there is no transition state barrier to charge exchange, and products such as $\mathrm{CH}_{3} \mathrm{OH}^{+}+\mathrm{H}$ and $\mathrm{CH}_{2} \mathrm{OH}_{2}^{+}+\mathrm{H}$ lie considerably below the transition state for synchronous exchange in the protonated methanol complex. So, it is most likely that $\mathrm{H}-\mathrm{H}$ exchange does not occur during reaction, and that even if it does, the products will not lead directly to neutral methanol.

\section{Relative destruction rates and fractional abundances}

Observations in the well-studied protostellar source IRAS 16293-2422 show that there is significantly more $\mathrm{CH}_{2} \mathrm{DOH}$ than $\mathrm{CH}_{3} \mathrm{OD}$, perhaps as much as 15 times more (Parise et al. 2004), as shown in Table 3, which also contains less dramatic results for the Orion Compact Ridge (OCR). Indeed, there appears to be more $\mathrm{CHD}_{2} \mathrm{OH}$ than $\mathrm{CH}_{3} \mathrm{OD}$ in IRAS 16293-2422, while in the Orion Compact Ridge, on the other hand, the two singly deuterated isotopomers of methanol are of similar abundance.

Although it is thought that the granular synthesis of $\mathrm{CH}_{2} \mathrm{DOH}$ is somewhat more efficient than that of $\mathrm{CH}_{3} \mathrm{OD}$ 
Table 3. Observations.

\begin{tabular}{lll}
\hline \hline & IRAS 16293-2422 & OCR \\
\hline $\mathrm{CH}_{2} \mathrm{DOH} / \mathrm{CH}_{3} \mathrm{OH}$ & $0.3( \pm 0.2)[1]$ & $0.01-0.06[2]$ \\
$\mathrm{CH}_{3} \mathrm{OD} / \mathrm{CH}_{3} \mathrm{OH}$ & $0.02( \pm 0.01)[1]$ & $0.04[3]$ \\
$\mathrm{CHD}_{2} \mathrm{OH} / \mathrm{CH}_{3} \mathrm{OH}$ & $0.06( \pm 0.05)[1]$ & - \\
$\mathrm{CD}_{3} \mathrm{OH} / \mathrm{CH}_{3} \mathrm{OH}$ & $0.014( \pm 0.014) / 0.008( \pm 0.006)[1]$ & - \\
$\mathrm{HDCO} / \mathrm{H}_{2} \mathrm{CO}$ & $0.15-0.3[4,5]$ & $0.14[6]$ \\
$\mathrm{D}_{2} \mathrm{CO} / \mathrm{H}_{2} \mathrm{CO}$ & $0.03-0.16[7]$ & $0.003[6]$ \\
\hline
\end{tabular}

1 Parise et al. (2004).

2 Jacq et al. (1993).

3 Mauersberger et al. (1988).

4 van Dishoeck et al. (1995).

5 Schöier et al. (2002).

6 Turner (1990).

7 Ceccarelli et al. (2001).

(Charnley et al. 1997; Caselli et al. 2002; Stantcheva \& Herbst 2003), a differential rate of depletion is also needed to reproduce the large asymmetry between the two in IRAS 162932422. So let us consider the relative destruction rates of $\mathrm{CH}_{3} \mathrm{OD}$ and $\mathrm{CH}_{2} \mathrm{DOH}$. Let us assume that protonation to form $\mathrm{CH}_{3} \mathrm{OHD}^{+}$and $\mathrm{CH}_{2} \mathrm{DOH}_{2}^{+}$occurs competitively. Following protonation, the dissociative recombination pathways that lead back to a methanol structure and an atom can produce the following isotopically distinct products:

$\mathrm{CH}_{3} \mathrm{OHD}^{+}+\mathrm{e}^{-} \longrightarrow \mathrm{CH}_{3} \mathrm{OH}+\mathrm{D}, \mathrm{CH}_{3} \mathrm{OD}+\mathrm{H}$,

and

$$
\mathrm{CH}_{2} \mathrm{DOH}_{2}^{+}+\mathrm{e}^{-} \longrightarrow \mathrm{CH}_{2} \mathrm{DOH}+\mathrm{H} \text {, }
$$

where we have utilized our analysis that $\mathrm{D}-\mathrm{H}$ exchange between the C- and O-ends of the methanol skeleton is inefficient during and after reaction. Thus, we see that there is an asymmetry built into the depletion: $\mathrm{CH}_{3} \mathrm{OD}$ can be destroyed via the mechanism whereas $\mathrm{CH}_{2} \mathrm{DOH}$ cannot be. This asymmetry was first recognized by Charnley et al. (1997) in their study of methanol deuteration in the Orion Compact Ridge. Of course, the importance of this asymmetry depends upon how large the methanol product channel is in the dissociative recombination of protonated methanol, and how competitive the $\mathrm{CH}_{3} \mathrm{OH}+\mathrm{D}$ channel is compared with the $\mathrm{CH}_{3} \mathrm{OD}+\mathrm{H}$ channel. In other studies, it has been shown that the removal of an $\mathrm{H}$ atom can be more efficient than that of a $\mathrm{D}$ atom (Jensen et al. 2000).

We have run some new protostellar models, starting immediately after the loss of grain mantles, to determine how severe the abundance gradients between pairs of deuterated isotopomers of methanol can become. A new gas-phase model that contains multiply deuterated species and an expanded number of chemical reactions has been used (Roberts et al. 2003). The network does not contain processes in which $\mathrm{D}$ and $\mathrm{H}$ atoms on methanol-type isotopomers can exchange. The initial fractional abundances of some normal species and the ratios of deuterated isotopomers to these normal species are listed in Table 4 . These initial abundances derive from a gas-phase plus accretion model for the cold $(10 \mathrm{~K})$ pre-protostellar phase,
Table 4. Initial conditions based mainly on a grain-surface chemistry model with an accreting $\mathrm{D} / \mathrm{H}$ ratio of 0.3 .

\begin{tabular}{lcll}
\hline \hline Species & $\begin{array}{c}\text { Abundance } \\
\text { (relative to } \mathrm{H})\end{array}$ & Isotopomer & Fractionation \\
\hline $\mathrm{H}_{2} \mathrm{O}$ & $1.0(-5)$ & $\mathrm{HDO}$ & 0.33 \\
& & $\mathrm{D}_{2} \mathrm{O}$ & 0.03 \\
$\mathrm{H}_{2} \mathrm{CO}$ & $2.0(-8)$ & $\mathrm{HDCO}$ & 0.28 \\
& & $\mathrm{D}_{2} \mathrm{CO}$ & 0.02 \\
$\mathrm{CH}_{3} \mathrm{OH}$ & $1.0(-7)$ & $\mathrm{CH}_{3} \mathrm{OD}$ & 0.18 \\
& & $\mathrm{CH}_{2} \mathrm{DOH}$ & 0.64 \\
& & $\mathrm{CH}_{2} \mathrm{DOD}$ & 0.11 \\
& & $\mathrm{CHD}_{2} \mathrm{OH}$ & 0.14 \\
& & $\mathrm{CHD}_{2} \mathrm{OD}$ & 0.03 \\
& & $\mathrm{CD}_{3} \mathrm{OH}$ & 0.012 \\
$\mathrm{H}_{2} \mathrm{~S}$ & $1.0(-10)$ & $\mathrm{CD}_{3} \mathrm{OD}$ & 0.0023 \\
& & $\mathrm{HDS}$ & 0.33 \\
& & $\mathrm{D}_{2} \mathrm{~S}$ & 0.03 \\
\hline
\end{tabular}

which is run until everything that can do so is frozen onto the grains (Roberts et al. 2003). Additional amounts of water, formaldehyde, methanol, and $\mathrm{H}_{2} \mathrm{~S}$ were added to account for surface chemistry, which is not considered in the model of Roberts et al. (2003). The initial fractionation ratios utilized derive from our gas-phase plus accretion model and the grain model of Stantcheva \& Herbst (2003) with a gas-phase atomic deuterium-to-hydrogen ratio of 0.3 . Initially, we assume that the temperature of both the gas and the dust after evaporation is $50 \mathrm{~K}$, and the gas density is $10^{6} \mathrm{~cm}^{-3}$. Species are assumed to evaporate via thermal desorption, using desorption energies from Hasegawa \& Herbst (1993) and Aikawa et al. (1997). Figure 7 shows the results for the ratios of the deuterated isotopomers to normal methanol as functions of time. It can be seen that the ratio for $\mathrm{CH}_{3} \mathrm{OD}$ declines more strongly over the first $3 \times 10^{5} \mathrm{yr}$ than does the ratio for $\mathrm{CH}_{2} \mathrm{DOH}$. Similarly, the ratio for $\mathrm{CH}_{2} \mathrm{DOD}$ declines more precipitously than does the ratio for $\mathrm{CHD}_{2} \mathrm{OH}$, while that for $\mathrm{CHD}_{2} \mathrm{OD}$ declines more rapidly than that for $\mathrm{CD}_{3} \mathrm{OH}$. Thus, it can be seen that the effect discussed in the body of the paper is making its presence known in the overall chemistry. Eventually all fractionation ratios decline since fractionation at a temperature of $50 \mathrm{~K}$ 


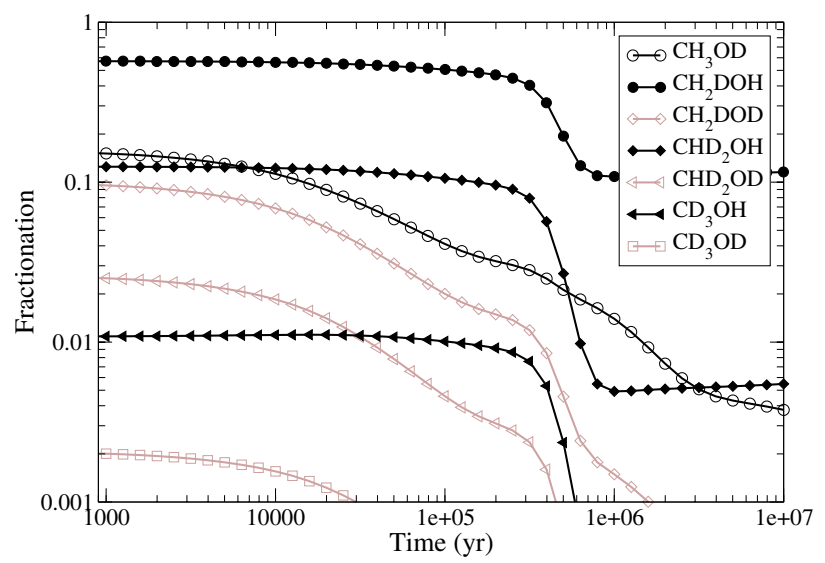

Fig. 7. Fractionation ratios of deuterated methanols to normal methanol plotted vs. time for a protostellar source. Lines in black are for the observed species. $T=50 \mathrm{~K}, n\left(\mathrm{H}_{2}\right)=10^{6} \mathrm{~cm}^{-3}$.

is nowhere near as large an effect as the initial ratios. Those methanol isotopomers with the deuterium in the methyl group $\left(\mathrm{CH}_{2} \mathrm{DOH}, \mathrm{CHD}_{2} \mathrm{OH}, \mathrm{CD}_{3} \mathrm{OH}\right)$, however, are still fractionated via the methyl ions $\mathrm{CH}_{2} \mathrm{D}^{+}, \mathrm{CHD}_{2}^{+}$and $\mathrm{CD}_{3}^{+}$. The exchange reactions between these ions and $\mathrm{HD}$ are endothermic in the reverse direction by $\sim 370 \mathrm{~K}$, which means that fractionation via this route is efficient at temperatures up to $\sim 60 \mathrm{~K}$ (see e.g., Roberts \& Millar 2000a).

When compared with the methanol observations of IRAS 16293-2422, the model yields excellent agreement at a time of $10^{5} \mathrm{yr}$, with the differences between computed and observed fractionation ratios for deuterated methanols within or very close to the observed uncertainties. Unfortunately, this timescale is five times longer than the age of the IRAS 162932422 protostar, as estimated by Ceccarelli et al. (2001). How can the rate of the chemistry be speeded up under these physical conditions? Increasing the density usually decreases the timescale for the chemistry, but in the case of hot-core chemistry, the gas is initially neutral and so the abundances of the species do not change much after evaporation until the abundance of molecular ions has built up. Because increasing the density reduces the ionisation fraction, it does not speed up the chemistry significantly. The most effective way to do that is to increase the cosmic ray ionisation rate (Hatchell et al. 1998). An increase in the cosmic ray ionisation rate from $1.3 \times 10^{-17} \mathrm{~s}^{-1}$ to one order of magnitude greater does indeed have the desired effect; reasonable agreement with observations now occurs after a few $\times 10^{4} \mathrm{yr}$. Support for a high ionisation rate in IRAS 16293-2422 is also provided by the detailed chemical model of Doty et al. (2004), which, however, does not contain deuterium fractionation.

But IRAS 16293-2422 is a complex source with evidence for a "hot-core" region within $\sim 150 \mathrm{AU}$ of the central object where $T \geq 100 \mathrm{~K}$ and $n\left(\mathrm{H}_{2}\right) \geq 10^{7} \mathrm{~cm}^{-3}$ (Ceccarelli et al. 2000; Schöier et al. 2002). Ceccarelli et al. (2001) have derived an $\mathrm{H}_{2} \mathrm{CO}$ abundance profile with two jumps: one at $\leq 700 \mathrm{AU}$, where the dust temperature reaches $50 \mathrm{~K}$, and one at $\sim 150 \mathrm{AU}$ where $T_{\text {dust }}=100 \mathrm{~K}$, while Schöier et al. (2002) have calculated that the methanol abundance jumps by a factor of $\sim 1000$

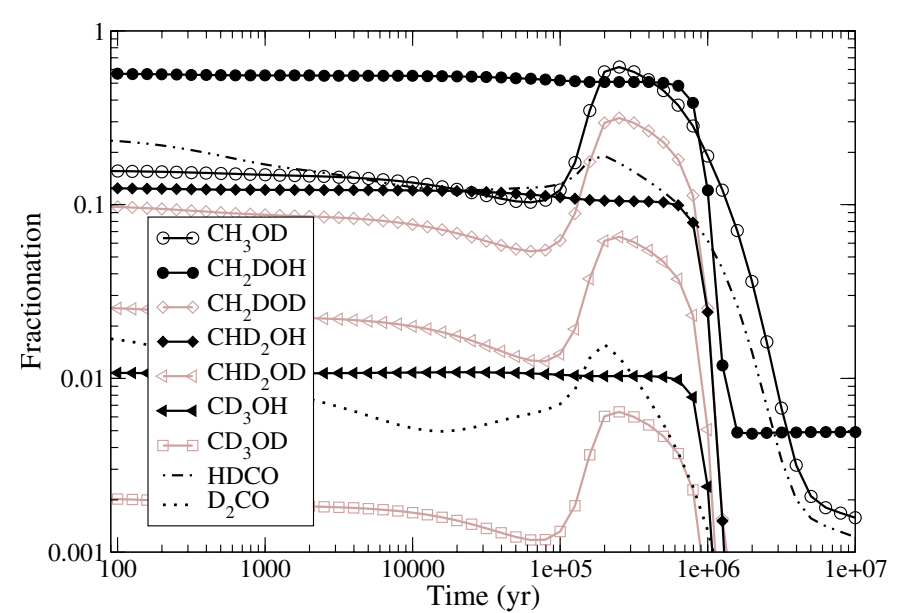

Fig. 8. As in Fig. 7, except that $T=100 \mathrm{~K}$, and $n\left(\mathrm{H}_{2}\right)=10^{7} \mathrm{~cm}^{-3}$.

in the hot core region, compared with the cooler, less dense envelope.

We have also, therefore, run the model at a temperature of $100 \mathrm{~K}$ and a density of $10^{7} \mathrm{~cm}^{-3}$ in order to simulate conditions within the hot-core region. For times greater than a few times $10^{4} \mathrm{yr}$, the methanol abundance in the gas-phase is calculated to be very similar to that derived by Schöier et al. (2002) in the hot-core region of IRAS 16293-2422 $\left(3 \times 10^{-7}\right)$. The fractionation results are shown in Fig. 8. At early times, there is little change in the gas-phase fractionation. Interestingly, we now see the opposite effect to that which we would expect: at times greater than $10^{5} \mathrm{yr}$ the relative abundance of those methanol species with an OD group actually increases, and these enhanced abundances last until almost $10^{6} \mathrm{yr}$ have passed. The reason for this effect is that at temperatures above $80 \mathrm{~K}$, all of the surface water evaporates during the first $10^{5} \mathrm{yr}$, whereas at $50 \mathrm{~K}$ the bulk of the water remains frozen. In the model run at $100 \mathrm{~K}$, therefore, protonation of $\mathrm{H}_{2} \mathrm{O}$ and $\mathrm{HDO}$ in the gas-phase leads to $\mathrm{H}_{3} \mathrm{O}^{+}$and $\mathrm{H}_{2} \mathrm{DO}^{+}$, and the high initial $\mathrm{HDO} / \mathrm{H}_{2} \mathrm{O}$ ratio (from the surface chemistry; see Table 4) leads to a high $\mathrm{H}_{2} \mathrm{DO}^{+} / \mathrm{H}_{3} \mathrm{O}^{+}$ratio in the gas. This high ratio, in turn, leads to additional fractionation throughout the reaction network. Based on the quantum chemical results discussed in this paper, only the methanol isotopomers with OD groups, however, are enhanced. As can be seen in Fig. 8, the $\mathrm{CH}_{3} \mathrm{OD}$ fractionation is, obviously, much larger than that observed by Parise et al. (2003) in IRAS 16293-2422, and the predicted $\mathrm{D}_{2} \mathrm{CO}$ fractionation is lower than that observed by Ceccarelli et al. (2001) in this source. On the other hand, perhaps this model is appropriate for the Orion Compact Ridge, where the temperature is at least $70 \mathrm{~K}$, and the $\mathrm{H}_{2} \mathrm{O}$ abundance is $\geq 10^{-5}$ (Wright et al. 1997). Of course, a better model for the Orion Compact Ridge would have to start with lower fractionation ratios for the methanol isotopomers.

The high abundances of gaseous water and HDO in the $100 \mathrm{~K}$ model are clearly important in leading to the very different result from our $50 \mathrm{~K}$ model. But are they reasonable for IRAS 16293-2422? Between 1000 and $10^{5} \mathrm{yr}$, the $\mathrm{H}_{2} \mathrm{O}$ fractional abundance from the model exceeds $7 \times 10^{-6}$, whereas Ceccarelli et al. (2000) determine the fractional 
Table 5. Altered initial abundances and fractionations for the "hot-core" region of IRAS 16293-2422.

\begin{tabular}{lcll}
\hline \hline Species & $\begin{array}{c}\text { Abundance } \\
\text { (relative to } \mathrm{H})\end{array}$ & Isotopomer & Fractionation \\
\hline $\mathrm{H}_{2} \mathrm{O}$ & $1.5(-6)$ & $\mathrm{HDO}$ & 0.01 \\
& & $\mathrm{D}_{2} \mathrm{O}$ & 0.001 \\
$\mathrm{H}_{2} \mathrm{CO}$ & $5.0(-8)$ & $\mathrm{HDCO}$ & 0.8 \\
& & $\mathrm{D}_{2} \mathrm{CO}$ & 0.16 \\
$\mathrm{CH}_{3} \mathrm{OH}$ & $2.0(-7)$ & & \\
\hline
\end{tabular}

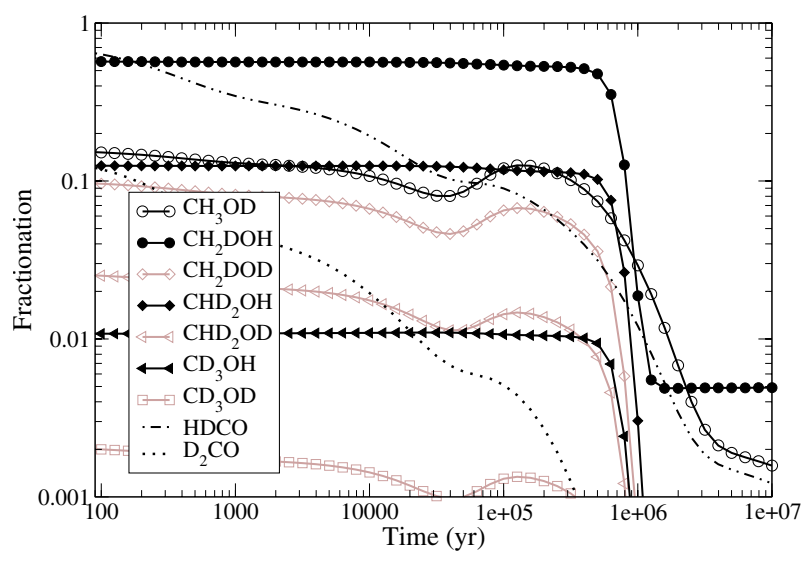

Fig. 9. As in Fig. 8, but using initial abundances from Table 5.

abundance at the centre of IRAS $16293-2422$ to be $3 \times 10^{-6}$. Also, searches for solid HDO have put its abundance $<0.2-$ $2 \%$ of $\mathrm{H}_{2} \mathrm{O}$ (Dartois et al. 2003; Parise et al. 2003), so we have investigated lowering both the initial abundance and fractionation of water on the grains. In particular, we have run a model where the initial abundances of three species (water, formaldehyde, and methanol) are constrained by observations towards the centre of IRAS 16293-2422, as shown in Table 5. In addition, the initial fractionation of water has been lowered, while that of $\mathrm{D}_{2} \mathrm{CO}$ has been increased to the highest ratio observed by Ceccarelli et al. (2001) in the envelope.

With the new initial abundances, after $10^{4} \mathrm{yr}$, the abundances of $\mathrm{H}_{2} \mathrm{O}$ and $\mathrm{CH}_{3} \mathrm{OH}$ are very similar to those observed $\left(3 \times 10^{-6}\right.$ and $3 \times 10^{-7}$, respectively), while the abundance of $\mathrm{H}_{2} \mathrm{CO}$ is within a factor of two of the observation. Results for the fractionation are shown in Fig. 9, where it can be seen that the lower initial abundances of $\mathrm{H}_{2} \mathrm{O}$ and $\mathrm{HDO}$ have removed the peaks in fractionation of $\mathrm{CH}_{3} \mathrm{OD}$ et al., seen in Fig. 8 at $10^{5}-10^{6}$ yr. Still, the new results show the fractionation ratio for $\mathrm{CH}_{3} \mathrm{OD}$ to remain roughly constant until $10^{6} \mathrm{yr}$. This result stems from the fact that there is still $\sim 4$ times more water in the gas-phase than in the first model run at $50 \mathrm{~K}$. Thus, at $2 \times 10^{4} \mathrm{yr}$ (the probable age of the IRAS 16293-2422 protostar) the $\mathrm{CH}_{2} \mathrm{DOH}, \mathrm{CHD}_{2} \mathrm{OH}$ and $\mathrm{CD}_{3} \mathrm{OH}$ relative abundances are in agreement with the observations of Parise et al. (2003), but $\mathrm{CH}_{3} \mathrm{OD}$ is 4.5 times higher. For $\mathrm{D}_{2} \mathrm{CO}$, despite its high initial abundance, the fractionation is still somewhat low.

In fact, the timescale for the chemistry may be even shorter in the hot-core region, since, with the assumption of a freefall velocity, the transit time for grains and molecules through the central $150 \mathrm{AU}$ region is only $300 \mathrm{yr}$ (Schöier et al. 2002).
This does not give sufficient time for much processing of the material evaporated from the grains to take place, so that our predictions are essentially the initial evaporated abundances which, for the deuterated methanols, are not too different from the results at $2 \times 10^{4} \mathrm{yr}$. On the other hand, the abundance of $\mathrm{D}_{2} \mathrm{CO}$ is much higher, and in better agreement with observation. In their recent survey of IRAS 16293, however, Cazaux et al. (2003) found significant amounts of complex Oand N-bearing species. When compared with the models of Rodgers \& Charnley (2001), this finding implies that the injected material has been processed over a timescale of $\sim 5 \times$ $10^{4} \mathrm{yr}$, although the timescale in chemical models of hot cores is sensitive to the cosmic ray ionisation rate (Hatchell et al. 1998).

Given all of these complications, it is obvious that IRAS $16293-2422$ is too complex a source for the relatively simple one-point models discussed here. More detailed models are clearly necessary, in which we will have to consider both the hot core and its envelope with at least a two-phase approach (see, e.g., Doty et al. 2004). Currently, we can only state that our best explanation of the observations of the deuterated isotopomers of methanol in IRAS 16293-2422 is that much of the methanol emission is coming from the region outside $150 \mathrm{AU}$.

A further test of the importance of differential depletion rates can be made when the spectrum of $\mathrm{CH}_{2} \mathrm{DOD}$ over a useful frequency range is measured in the laboratory, a task currently being pursued at Ohio State. If the model shown in Fig. 7 is correct, the fractionation ratio of this doubly deuterated species will be significantly less than that of $\mathrm{CHD}_{2} \mathrm{OH}$, but still large enough $(\approx 0.02)$ that $\mathrm{CH}_{2}$ DOD should be detectable.

Acknowledgements. This research was partly supported by grants-inaid for Scientific Research on Priority Areas from the Ministry of Education, Science, and Culture, Japan. Most of the quantum chemical calculations were carried out using the computer center of the Institute for Molecular Science, Japan. The Astrochemistry Program at The Ohio State University is supported by The National Science Foundation (US).

\section{References}

Adams, N. G., \& Babcock, L. M. 1994, ApJ, 434, 184

Aikawa, Y., Umebayashi, T., Nakano, T., \& Miyama, S. M. 1997, ApJ, 486, L52

Bacmann, A., Lefloch, B., Ceccarelli, C., et al. 2003, ApJ, 585, L55

Bates, D. R. 1993, MNRAS, 263, 369

Butler, J. N., Babcock, L. M., \& Adams, N. G. 1997, Mol. Phys., 91, 81

Caselli, P., Stantcheva, T., Shalabiea, O., Shematovich, V. I., \& Herbst, E. 2002, P\&SS, 50, 1257

Cazaux, S., Tielens, A. G. G. M., Ceccarelli, C., et al. 2003, ApJ, 593, L54

Ceccarelli, C., Loinard, L., Castets, A., Tielens, A. G. G. M., \& Caux, E. 2000, A\&A, 357, L9

Ceccarelli, C., Loinard, L., Castets, A., et al. 2001, A\&A, 372, 998

Ceccarelli, C., Vastel, C., Tielens, A. G. G. M., et al. 2002, A\&A, 381, L17

Charnley, S. B., Tielens, A. G. G. M., \& Rodgers, S. D. 1997, ApJ, 482, L203

Dartois, E., Thi, W.-F., Geballe, T. R., et al. 2003, A\&A, 399, 1009 
Doty, S. D., Schöier, F. L., \& van Dishoeck, E. F. 2004, A\&A, 418, 1021

Dunning, Jr. T. H. 1989, J. Chem. Phys., 90, 1007

Frisch, M. J., et al. 1998, Gaussian 98, Revision A.11 (Pittsburgh: Gaussian)

Guberman, S. L. 2003, Dissociative Recombination of Molecular Ions with Electrons (Dordrecht: Kluwer)

Hasegawa, T. I., \& Herbst, E. 1993, MNRAS, 261, 83

Hatchell, J., Thompson, M. A., Millar, T. J., \& MacDonald, G. H. 1998, A\&A, 338, 713

Herbst, E. 1982, Chem. Phys., 65, 185

Herbst, E., Terzieva, R., \& Talbi, D. 2000, MNRAS, 311, 869

Herd, C. R., Adams, N. G., \& Smith, D. 1990, ApJ, 349, 388

Holbroook, K. A., Pilling, M. J., \& Robertson, S. H. 1996, Unimolecular Reactions (New York: John Wiley)

Jacq, T., Walmsley, C. M., Mauersberger, R., et al. 1993, A\&A, 271, 276

Jensen, M. J., Bilodeau, R. C., Safvran, C. P., et al. 2000, ApJ, 543, 764

Jodkowski, J. T., Rayez, M.-T., Rayez, J.-C., Berces, T., \& Dobe, S. 1999, J. Phys. Chem. A, 103, 3750

Kline, J. M., \& Penner, S. S. 1982, Proc. Int. Symp. Shock Tubes Waves, 13,869

Lendvay, G., Berces, T., \& Marta, F. 1997, J. Phys. Chem. A, 101, 1588
Mauersberger, R., Henkel, C., Jacq, T., \& Walmsley, C. M. 1988, A\&A, 194, L1

Millar, T. J. 2003, Space Sci. Rev., 106, 73

Parise, B., Ceccarelli, C., Tielens, A. G. G. M., et al. 2002, A\&A, 393, L49

Parise, B., Simon, T., Caux, E., et al. 2003, A\&A, 410, 897

Parise, B., Castets, A., Herbst, E., et al. 2004, A\&A, 416, 159

Roberts, H., \& Millar, T. J. 2000a, A\&A, 361, 388

Roberts, H., \& Millar, T. J. 2000b, A\&A, 364, 780

Roberts, H., Herbst, E., \& Millar, T. J. 2003, ApJ, 591, L41

Rodgers, S. D., \& Charnley, S. B. 2001, ApJ, 546, 324

Semaniak, J., Larson, A., Le Padellec, A., et al. 1998, ApJ, 498, 886

Schöier, F. L., Jorgensen, J. K., van Dishoeck, E. F., \& Blake, G. A. 2002, A\&A, 390, 1001

Smith, I. W. M. 1980, Kinetics and Dynamics of Elementary Gas Reactions (London: Butterworth)

Stantcheva, T., \& Herbst, E. 2003, MNRAS, 340, 983

Tomashevsky, M., Herbst, E., \& Kraemer, W. P. 1998, ApJ, 498, 728

Turner, B. E. 1990, ApJ, 362, L29

van Dishoeck, E. F., Blake, G. A., Jansen, D. J., \& Groesbeck, T. D. 1995, ApJ, 447, 760

Wright, M. C. H., Plambeck, R. L., \& Wilner, D. J. 1996, ApJ, 469, 216 